\title{
Gene targeting of the aggregation stage cAMP receptor cAR1 in Dictyostelium
}

\author{
T. Julia Sun and P.N. Devreotes ${ }^{1}$ \\ Department of Biological Chemistry, The Johns Hopkins Unversity School of Medicine, Baltimore, Maryland 21205 USA
}

\begin{abstract}
cAR1, a G-protein-linked surface cAMP receptor, plays a central role in the development of Dictyostelium. To investigate its role, we sought to target the cAR1 gene by homogolous recombination. Transformation of these amoebas with appropriately designed vectors results in integration into the $c A R 1$ locus with high frequency. cAR1 "null" mutants, resulting from double crossover events, fail to bind or sense cAMP and arrest in early development. The null mutants can be rescued by constitutive expression of a wild-type cAR1 cDNA.

Carboxy-terminal deletion mutants, derived from single crossover events, express a truncated form of cAR1 that binds and senses cAMP. These cells proceed through the developmental program, albeit with a delay. Constitutive expression of a similar truncated form of cAR1 also rescues the null mutant. These observations prove that cAR1-mediated signal transduction controls the development of Dictyostelium and allow structural/functional studies of a G-protein-linked receptor in its natural context.
\end{abstract}

[Key Words: cAMP receptor; Dictyostelium; gene targeting]

Received November 11, 1990; revised version accepted January 16, 1991.

When deprived of a nutrient source, Dictyostelium amoebas synchronously aggregate into a multicellular organism and differentiate into stalk or spore cells (Gerisch 1987; Janssens and Van Haastert 1987; Devreotes 1989). The spontaneous aggregation is mediated by a signaling system in which binding of extracellular CAMP to surface receptors triggers activation of adenylate cyclase. Newly synthesized cAMP is then secreted, completing a positive feedback loop that, when coupled to a rapid, reversible adaptation of the response, causes cAMP levels to oscillate. The oscillatory signal is relayed to distal cells and the chemotactically sensitive cells aggregate in response to the propagated cAMP waves. Many genes that are expressed in early development during aggregation require the cAMP oscillations and are suppressed by a constant level of extracellular cAMP. In contrast, genes that are expressed in later development as the cell types emerge require a constant level of extracellular cAMP (Schaap and van Driel 1985; Gomer et al. 1986; Haribabu and Dottin 1986; Oyama and Blumberg 1986; Kimmel 1987; Mann and Firtel 1987). Mutants with defective oscillators fail to differentiate, but can be rescued by subjecting them to first periodic and then continuous exogenous cAMP.

Many of these cAMP-induced responses appear to be mediated by cAR1, a G-protein-coupled receptor that detects extracellular cAMP (Klein et at. 1988). cAR1 is coupled to the $G \alpha 2$ protein, which in turn appears to be coupled to a phospholipase C (PLC) /Van Haastert 1984; Newell et al. 1988; Van Haastert et al. 1989). Inactivation of G $\alpha 2$ blocks all cAMP-mediated responses and

${ }^{1}$ Corresponding author. halts the developmental program (Kumagai et al. 1989). Stimulation with cAMP induces an extensive phosphorylation of cAR1. The kinetics and dose dependence of this phosphorylation reaction suggest that it causes adaptation, a gradual uncoupling of the receptor from $\mathrm{G} \alpha 2$. Adaptation and deadaptation, which occur upon stimulus removal, play a central role in regulation of the cAMP oscillator (Devreotes and Sherring 1985; Klein et al. 1985; Vaughan and Devreotes 1988).

We have described several $C A R 1$ antisense cell lines that express negligible levels of $c A R 1$ protein (Sun et al. 1990). The lines fail to differentiate when starved and are unresponsive to cAMP as a chemoattractant or stimulator of intracellular second messengers. Although these observations have been satisfying, the technique of antisense mutagenesis does formally leave open alternate interpretations. For instance, we have recently discovered that there are genes for four subtypes of cAMP receptors: cAR1, cAR2, cAR3, and cAR4 (Saxe et al. 1990). It is conceivable that certain phenotypic consequences of the $C A R 1$ antisense mutagenesis are attributable to loss of a cAR besides cAR1. Furthermore, we were not able to determine whether certain "residual" wild-type phenotypes, such as the tendency of a minor fraction of the antisense cells to aggregate, were merely due to incomplete inhibition of $c A R 1$ expression or represented a function of another cAR.

To address these issues, we created cell lines in which the endogenous $C A R 1$ was disrupted by homologous recombination. Cell lines in which $c A R 1$ is completely inactivated display a similar phenotype to the antisense lines except that the failure to aggregate is absolute. These null cell lines serve as hosts for expression of wild- 
type and altered $c A R 1$ genes. We also show that mutated versions of $c A R 1$ can be crossed into the $c A R 1$ genomic locus of wild-type cells switching the form of $c A R 1$ protein expressed from the endogenous promoter. Together, these advances provide a convenient system for a genetic analysis of the role and function of a G-protein-linked receptor in chemotaxis and development.

\section{Results}

\section{Strategies for targeting of cAR1 gene}

Two different targeted recombination strategies were used to either inactivate the endogenous copy of the $c A R 1$ gene or replace it with a mutationally altered variant. In the first, designed to produce mutants containing a copy of the marker gene within the sixth transmembrane domain of the $c A R 1$-coding sequence (after residue 208), cells were transformed with the linearized vector illustrated In Figure 1A. In principle, this strategy requires a double crossover event for insertion of the marker into the genomic copy of $c A R 1$. In the second, illustrated in Figure 1B, cells were transformed with a circular vector containing an internal fragment of the $c A R 1$ cDNA. This vector was designed to integrate by a single crossover event resulting in tandem repeat of the endogenous $c A R 1$ gene. The most $5^{\prime}$ copy is driven by the endogenous promoter and is deleted on its carboxyterminal end (after residue 317 ). The most $3^{\prime}$ copy has no promoter and is deleted on its amino-terminal end (Fig. 1B). Note that the resultant genomic structure in B has the potential to excise itself by homologous recombination, whereas that in A does not.

\section{Polymerase chain reaction analysis}

Because we expected to obtain "random" integrations as well as the predicted events, various polymerase chain
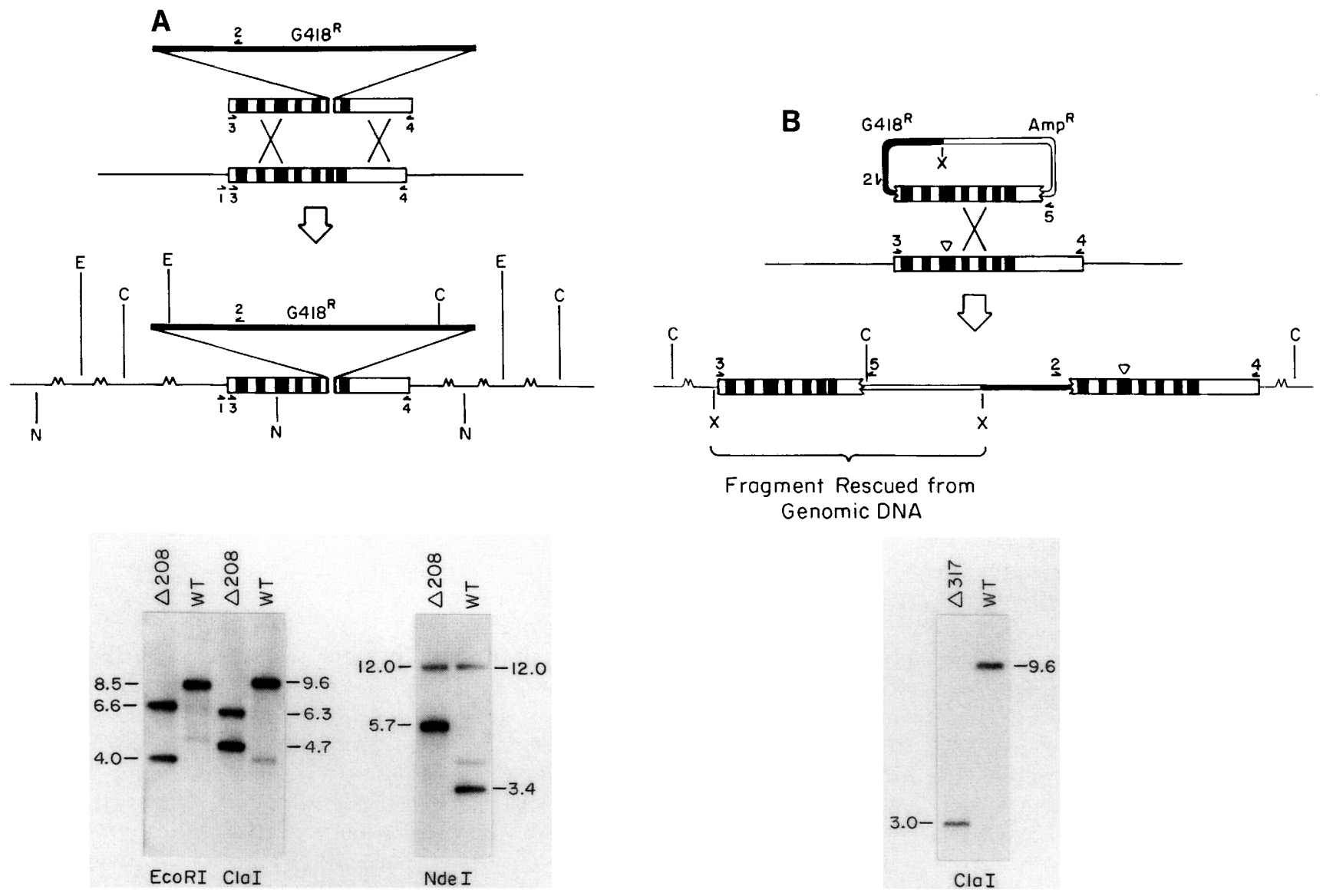

Figure 1. Strategy for $c A R 1$ gene targeting and DNA blot analysis of the resultant mutants. Alteration of $c A R 1$ gene by a double crossover event $(A)$ or by a single crossover event $(B)$ is presented at top. Relevant primers (1-5) used in PCR screening are shown. The thin horizontal line is genomic DNA. The $C A R 1$-coding sequence is illustrated as an open bar; vertical solid bars indicate the transmembrane domains. The G $418^{\mathrm{R}}$ cassette is illustrated as a heavy solid line; the bacterial plasmid is a heavy open line. The position of the intron in the third transmembrane domain is indicated with an open triangle. Sites for EcoRI $|\mathrm{E}|, \mathrm{ClaI} \mid \mathrm{C}), \mathrm{NdeI}(\mathrm{N})$, and $X b a I(X)$ are indicated. At bottom, total DNAs of $\Delta 208, \Delta 317$, and WT (HC6) were isolated, digested with restriction enzymes, size-fractionated on agarose gels, and transferred to nylon membranes. The membranes were hybridized to random-primed full-length $c A R 1$ cDNA probe $(A)$ or ${ }^{32} \mathrm{P}$-labeled primer $3(B)$, washed, and placed on X-ray film. The numbers on the side of blots indicate DNA fragment length in $\mathrm{kb}$. 
reaction (PCR) strategies were devised to permit screening of heterogeneous pools of individual transformants for detection of homologous recombination events (for the predicted double crossover events, refer to Fig. 1A). Primer 1 is located within the $5^{\prime}$ end of the $c A R 1$ gene; primer 2 is located within the inserted $G 418^{\mathrm{R}}$ cassette. A crossover within the $5^{\prime}$ arm of the transforming vector will create a unique PCR template of $0.9 \mathrm{~kb}$. Wild-type cells or cells carrying random insertions will not contain this template. A similar strategy, involving primers 3 and 5 , was used to screen for potential mutants resulting from transformation with the single crossover vector (Fig. 1B). In both cases, individual positive clones were checked with primers 3 and 4 for the absence of intact CAR1 gene. We initially tested pools of 3-12 transformants and found that most pools contained positive bands (not shown). Therefore, individual transformants from these pools were analyzed further by DNA blot.

\section{DNA blot analysis}

To diagnose the anticipated double crossover integration event restriction enzymes with one site within the inserted sequence, such as EcoRI and ClaI, or with one site in the $c A R 1$-coding sequence, such as NdeI, were used. Analysis of one of the positive transformants, designated $\Delta 208$, is illustrated in Figure 1A. The 8.5-kb wild-type EcoRI fragment is missing in the mutant and replaced by two smaller fragments of predicted size $(6.6$ and $4.0 \mathrm{~kb})$. Also the 9.6-kb wild-type ClaI fragment is missing in the mutant and replaced by two smaller fragments of predicted size (6.3 and $4.7 \mathrm{~kb}$ ). Digestion with NdeI, which cuts only once in the $C A R 1$ gene yielded an unaltered $5^{\prime}$ fragment of $12 \mathrm{~kb}$, whereas the $3.4-\mathrm{kb}$ wild-type $3^{\prime}$ fragment was replaced by a $5.7-\mathrm{kb}$ fragment in the mutant. These results are completely consistent with the scheme depicting a double crossover event resulting in integration of a single copy of the linear transforming vector. The same transforming vector was used to produce equivalent $\Delta 208$ transformants in strains $\mathrm{HC} 6, \mathrm{AX} 3$, and HPS400 (Fig. 1A). A discussion of the frequencies of production of these and alternative mutations is presented below.

A ClaI site adjacent to the $3^{\prime}$ end of the $c A R 1$ insert in the vector was chosen to diagnose the expected single crossover integration event. Analysis of one of the positive transformants, designated $\Delta 317$, is illustrated in Figure 1B. When probed with oligomer 3 , the wild-type 9.6$\mathrm{kb}$ ClaI fragment is replaced with a $3.0-\mathrm{kb}$ fragment in the mutant cell lines. It was also possible to recover and sequence the mutant $c A R 1$ locus. Genomic DNA from the $\Delta 317$ cells was digested with $X b a I$ followed by ligation and transformation of Escherichia coli. Note in Figure 1B that the predicted $X b a I$ fragment would contain the $5^{\prime}$ end of the $C A R 1$ gene linked to the truncated $C A R 1$ cDNA and the pBSA15 plasmid. Sequence analysis of the recovered plasmids showed this expected structure. Furthermore, no intron was present within the CAR1 region. These observations illustrate that the circular vector integrated into the endogenous $c A R 1$ gene by homologous recombination and the point of crossover was $5^{\prime}$ to the intron. A number of $\Delta 317$ transformants were also probed with a full-length $c A R 1 \mathrm{cDNA}$. Several copies of the marker gene, ranging from two to five, were found to be inserted between the illustrated junction fragments (data not shown).

\section{Reintroduction of cAR1 into the 4208 mutants}

Several strategies were employed to reintroduce a functional $c A R 1$ gene into the various $\Delta 208$ mutants. First, in the thymidine-requiring HP400 cell line, we utilized the THYl gene, which complements the thymidine auxotrophy, as a second marker (Dynes and Firtel 1989). Second, as $\Delta 208$ transformants grow poorly on higher concentrations of G418 $(40 \mu \mathrm{g} / \mathrm{ml})$, "retransformed" clones could be selected on high G418 concentrations.

The mutant cell lines were transformed again with $c A R 1$ expression vectors, containing the $C A R 1$ cDNA driven constitutively by the actin 15 promoter. Previous experiments have shown that in wild-type cells, constitutive expression of a full-length or a truncated form (at residue 311) of cAR1 from these vectors is not deleterious for growth or development (R. Johnson, A. Kimmel, and P. Devreotes, unpubl.). Transformants that were able to survive without thymidine (in strain HPS400) or were resistant to higher concentrations of G418 (in strain HC6) were screened for successful complementation by observing their ability to aggregate. The DNA blot analysis of one of these aggregation-positive transformants, designated [CAR1], is illustrated in Figure 2. Note that the endogenous $C A R 1$ gene is absent and the disrupted copy is present, exactly as in $\Delta 208$ cells, as evidenced in $E c O R I$ and $X b a I$ digests. However, these cells now contain, in addition, 5-10 copies of the cAR1 expression vector presumably integrated at a single nonhomologous site as evidenced by the heavily hybridizing bands. A similar complementation was carried out with a $3^{\prime}$ deleted version of the $c A R 1$ expression vector creating the cell line designated [CAR1 $\Delta 311$ ] (Fig. 2).

\section{Expression of cAR $1 m R N A$}

Expression of $c A R 1$ mRNA in the wild-type and $\Delta 208$ cells was analyzed during starvation (Fig. 3). The level of the major wild-type mRNA $(2 \mathrm{~kb})$ peaked at $3 \mathrm{hr}$ and declined by $6 \mathrm{hr}$, at which time a secondary RNA $(2.1 \mathrm{~kb})$ appeared (Saxe et al. 1990). As anticipated, the $\Delta 208 \mathrm{mu}$ tant does not produce these full-length mRNAs (Fig. 3A). When a 3 ' fragment of $c A R 1$ was used as a probe, both bands were absent; a very minor $\sim 1 \mathrm{~kb}$-band, which may have been produced from the $G 418^{\mathrm{R}}$ cassette promoter, was detected. When a $5^{\prime}$ fragment was used as a probe, a 1.9-kb band was detected. This 1.9-kb mRNA is thought to initiate in the endogenous cAR1 promoter and terminate in the actin 15 terminator of the $\mathrm{G} 418^{\mathrm{R}}$ cassette (see Fig. 1A). The appearance of this partial $c A R 1$ mRNA was greatly delayed compared with the wild type. Nevertheless, these observations suggest that functional $c A R 1$ protein is not essential for expression of its early tran- 


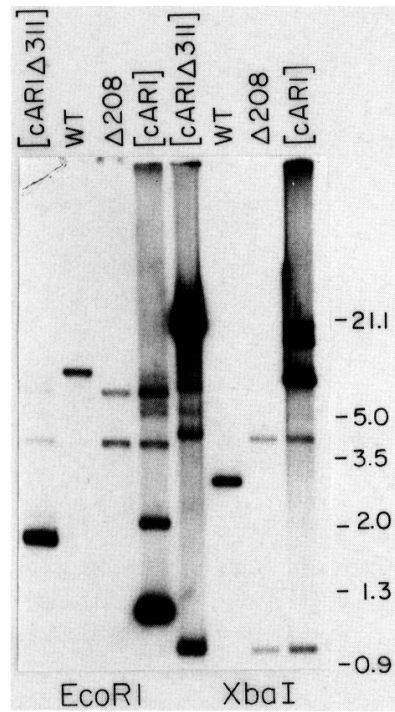

Figure 2. DNA blot analysis of retransformed $\triangle 208$ cell lines. Genomic DNA from cell lines WT, $\Delta 208$, [cAR1], and [cAR1 $\Delta 311$ ] was isolated, digested with EcoRI (left four lanes) or XbaI (right four lanes), and probed with random-primed full-length cAR1 cDNA. The numbers on the side of blots indicate DNA fragment length in $\mathrm{kb}$.

script, although it is required for the late $2.1-\mathrm{kb}$ mRNA that appears from $6 \mathrm{hr}$ until the final aggregation.

The $\Delta 317$ mutants expressed a predominant mRNA of $\sim 4.5 \mathrm{~kb}$ and a series of apparent degradation fragments. This mRNA is thought to result from a fusion of the amino terminus of $C A R 1$ to the plasmid portion of the transforming vector. Calculations indicate that this mRNA may terminate within the promoter of the G418 ${ }^{\mathrm{R}}$ cassette (Fig. 1B). This fused mRNA is expressed maximally at $3 \mathrm{hr}$, similar in timing to the endogenous wildtype mRNA. A similar sized band appears in late development $_{\text {; }}$ it peaks slightly later $(\sim 21 \mathrm{hr})$ than the $2.1-\mathrm{kb}$ band in wild-type $(\sim 18 \mathrm{hr})$ cells. When $\Delta 208$ mutants were rescued with the overexpression vectors creating cell lines designated [CARl] (data not shown) or [CAR1A311] (Fig. 3B), a high level of corresponding mRNA was observed throughout the developmental program.

\section{Expression of cAR1 protein and cell-surface cAMP binding}

The profile of expression of the $C A R 1$ protein in these transformants was analyzed with antisera specific to the last 18 amino acids of $c A R 1$. In wild-type cells, typical immunoblots show an increased production of $C A R 1$ antigen during early development that peaks at $6-8 \mathrm{hr}$. No detectable $c A R 1$ antigen was present in the $\Delta 208$ or the $\Delta 317$ mutants at any stage of starvation (Fig. 4). The [CAR1] cells contained a high level of $c A R 1$ antigen during growth and development.
Corresponding to the increase in $C A R 1$ protein, parental strains typically display a 15 -fold increase in cAMPbinding activity with a peak at 7-8 hr of development (Fig. 5). Under a variety of conditions, in multiple experiments similar to that shown in Figure 5, the $\Delta 208 \mathrm{mu}$ tants failed to display any significant cAMP-binding activity. The absence of $c A R 1$ antigen and cAMP-binding activity in the $\triangle 208$ mutants is consistent with the RNA blot analysis, which revealed only a partial $c A R 1$ mRNA. Even if an undetected fragment of $c A R 1$ protein is present, termination within the sixth transmembrane domain should completely inactivate cAMP-binding activity; studies of the $\beta$-adrenergic receptor have indicated that all of its seven transmembrane domains are needed for ligand-binding activity (Dixon et al. 1987). In contrast, the $\Delta 317$ mutant did develop binding activity, although its appearance was delayed. The [cAR1 $\Delta 311]$ cells showed high binding activity throughout development (Fig. 5). The binding activity of the $\Delta 317$ and [CARl $\triangle 311$ ] mutants was characterized by photoaffinity labeling. As illustrated in Figure 5B, rather than the 40$\mathrm{kD}$ polypeptide labeled in the wild type, in the $\Delta 317$ cells the cAMP-binding activity was associated with a poly-

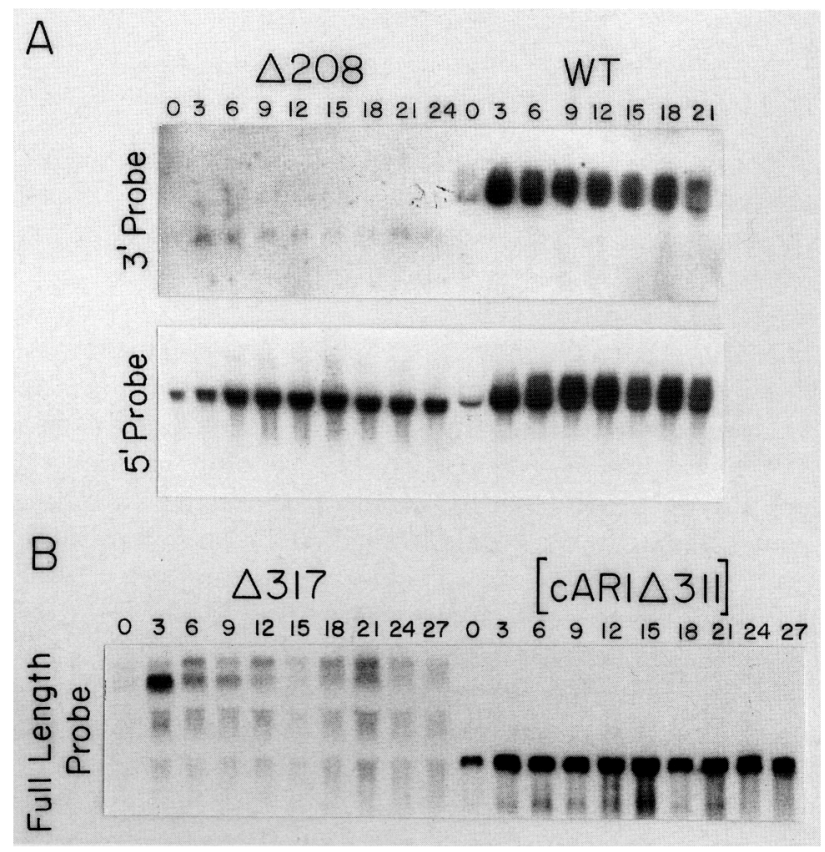

Figure 3. $c A R 1$ blot analysis of strains $\Delta 208, \Delta 317$, [cAR1 $\Delta 311$ ], and wild-type cell (HC6). Cells were grown in HL-5 with the appropriate amount of G418 (see Materials and methods), washed, and placed on the surface of a non-nutrient agar plate at $6.4 \times 10^{5} \mathrm{cell} / \mathrm{cm}^{2}$. Wild-type cells completed development by $24 \mathrm{hr}$, and $\Delta 317$ and [cARl $\Delta 311$ ] by $27 \mathrm{hr}$. Cells were washed off the plate at each specified hour, and total RNA was isolated, size-fractionated in formaldehyde agarose gels, and transferred to nylon membranes. Random-primed 5' (nucleotides 22-539) or 3' (nucleotides 904-1179) fragments of cAR1 cDNA were used as probes. Major band(s) in wild type are 2.0 and $2.1 \mathrm{~kb}$; in $\Delta 208,1.9\left(5^{\prime}\right.$ probe) and $\sim 1.0 \mathrm{~kb}\left(3^{\prime}\right.$ probe); in $\Delta 317,4.5 \mathrm{~kb}$; in [cARl $\Delta 311], \sim 1.9 \mathrm{~kb}$. 


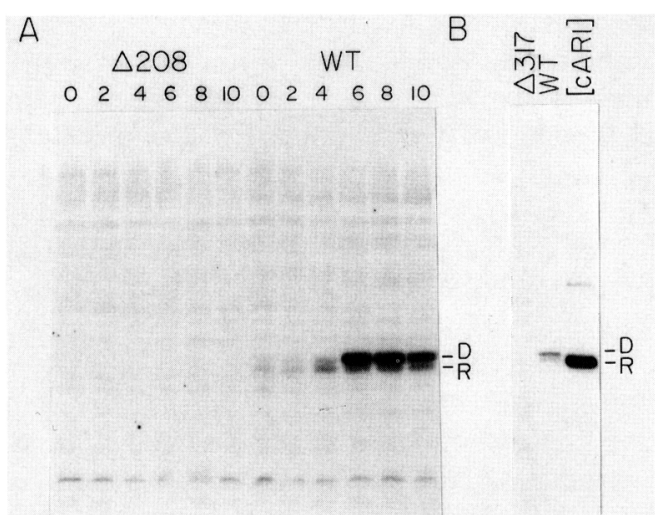

Figure 4. Immunoblot of $c A R 1$ in $\triangle 208, \triangle 317$, and [cAR1] cells. Cells were washed and allowed to develop in shaken suspension in $A$ or on agar surface $(B)$. In $B, \Delta 317$ and wild-type (WT) cells were harvested at $8 \mathrm{hr}$, whereas [cAR1] cells were harvested at $0 \mathrm{hr}$. Ammonium sulfate membranes were prepared and subjected to SDS-PAGE gel electrophoresis and transferred to nitrocellulose for immunoblotting.

peptide of $27 \mathrm{kD}$ and in the [CAR1 $\Delta 311]$ cells it was associated with an overexpressed $23-\mathrm{kD}$ polypeptide.

\section{Phenotypic consequences of cARl disruption or replacement}

When examined under a variety of standard developmental conditions, the $\Delta 208$ mutants remained as a smooth monolayer of cells; no signs of development appeared even after 2 weeks of observation. The $\Delta 317$ and [cAR1 $\Delta 311]$ mutants appeared normal when grown on and allowed to clear bacteria plates; however, on nonnutrient agar dishes, which allow more synchronous development, these cell lines were delayed. Constitutive overexpression of cARl in the $\Delta 208$ cells returned the phenotype nearly to that of the parental cell. Normal waves and streams were observed, and a large fraction of the cells completed the developmental program.

As wild-type cells differentiate, they develop cAMP chemotactic sensitivity. Peak activity coincides closely with the maximal expression of cAR1 (Table 1). When the $\Delta 208$ mutant was examined in multiple tests in several cAMP chemotaxis asays, it failed completely to respond within the sensitive time and dose range of wildtype cells. The cells, however, retained chemotactic sensitivity to folate, a chemoattractant for growth stage cells. The [cAR1] transformant regained its chemotactic sensitivity to CAMP. In addition, the amino-terminal four-fifths of cARl appears to be sufficient for chemotaxis to cAMP, as the $\Delta 317$ as well as the [CAR1 1311 ] mutants are nearly as competent as wild type. It was surprising to note that $\Delta 208$ cells began to develop chemotactic sensitivity to cAMP after 13-16 hr of starvation. These responses were weak and required higher concentrations of the chemoattractant. The responses, however, appeared to be specific as equal concentrations of 5' AMP were inactive. Because cAR1 cannot be ex-
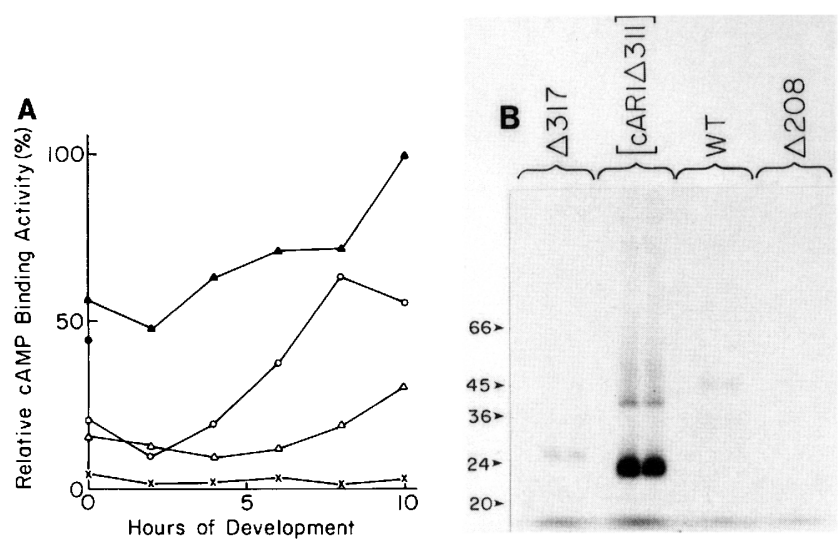

Figure 5. cAMP-binding activity and photoaffinity labeling of $\Delta 208, \Delta 317$, [cAR1 $\Delta 311]$, and [cAR1] cells. (A) Cells were developed as described in Fig. $3 .{ }^{3} \mathrm{H}$-labeled cAMP-binding activity of $\Delta 208(\mathrm{X}), \Delta 317(\Delta),[\mathrm{cAR} 1 \Delta 311](\Delta), \mathrm{WT}(O)$, and [cAR1] $(O)$ was determined and normalized to maximal binding activity of [cAR1 $\Delta 311]$. (B) Undeveloped cells $(0 \mathrm{hr})$ of the four lines were subjected to ${ }^{32}$ P-labeled 8-azido-cAMP photoaffinity label. Ammonium sulfate membranes were then prepared, subjected to SDS-PAGE, and autoradiographed for 6 days. Each group contains three lanes. The left lane of each group shows nonspecific labeling; right lanes show specific labeling. Size markers are indicated on the left side of the gel. The higher molecular weight band present in [CAR1 1311 ] is its dimer form.

pressed, these results suggest that one of the other cARs is mediating this function.

\section{Dependence of gene expression on cAR1}

Studies of the effects of extracellular cAMP on development suggest that surface cAMP receptors regulate the expression of multiple genes at each stage of the program. The time course of expression of several typical genes was monitored in wild-type and cARl mutant cell lines to document initially that cARl plays a key role in these processes.

Phosphodiesterase $(P D E)$ is one of the genes that plays an important role in modulating the extracellular cAMP concentration during development. Wild-type cells expressed the three distinct $P D E$ mRNA species of $1.9 \mathrm{~kb}$ (at $t=0$ ), $2.4 \mathrm{~kb}$ (early development), and $2.2 \mathrm{~kb}$ (at late development) as reported (Faure et al. 1990). The $\Delta 208$ mutant expressed the 1.9- and $2.4-\mathrm{kb}$ forms that peaked at a much later time in development $(\sim 15 \mathrm{hr})$ than the wild-type cells $(\sim 3-6 \mathrm{hr})$ but not the $2.2-\mathrm{kb}$ form (Fig. 6$)$. The $\triangle 317$ mutant has a nearly normal spectrum of $P D E$ mRNAs during development, except the late mRNA $(2.2$ $\mathrm{kb})$ was delayed by $\sim 3 \mathrm{hr}$. The [cARl $\Delta 311$ ] mutant displayed normal early $P D E$ mRNAs; however, the mRNA signal became stronger by $9 \mathrm{hr}$, and after a short decline, a very high level of mRNA reappeared and plateaued during late development.

Developing cells sequentially express a series of cARs (Saxe et al. 1990). In wild-type cells the major $c A R 3$ mRNA peaked at $6 \mathrm{hr}$ and, later, at $15 \mathrm{hr}$, displayed a 
Table 1. Chemotaxis response toward cAMP during development

\begin{tabular}{|c|c|c|c|c|c|c|c|c|c|c|c|c|c|c|c|c|c|c|c|c|c|c|}
\hline \multirow{2}{*}{$\begin{array}{l}-\log [\mathrm{cAMP}] \\
\text { (hr) }\end{array}$} & \multicolumn{4}{|c|}{$\begin{array}{l}\text { Wild type } \\
(\text { HC6) (\%) }\end{array}$} & \multicolumn{5}{|c|}{$\Delta 208(\%)$} & \multicolumn{4}{|c|}{$\Delta 317(\%)$} & \multicolumn{4}{|c|}{$\begin{array}{c}{[\mathrm{cAR} 1 / \Delta 311]} \\
(\%)\end{array}$} & \multirow{2}{*}{$\begin{array}{c}{[\text { cAR } 1]} \\
|\%|\end{array}$} & \multicolumn{4}{|c|}{$\begin{array}{c}\text { Wild type } \\
\text { (HPS400) (\%) }\end{array}$} \\
\hline & 8 & 7 & 6 & 5 & 7 & 6 & 5 & 4 & 3 & 8 & 7 & 6 & 5 & 8 & 7 & 6 & 5 & & 8 & 7 & 6 & 5 \\
\hline 5.0 & 0 & 8 & 59 & 83 & & & & & & 0 & 15 & 51 & 69 & 2 & 19 & 20 & 19 & & & & & \\
\hline 5.5 & 25 & 100 & 97 & 60 & 0 & 0 & 0 & & & & & & & & & & & & & & & \\
\hline 6.0 & & & & & & & & & & & & & & & & & & & 27 & 38 & 96 & 100 \\
\hline 6.5 & 41 & 99 & 100 & 100 & & & & & & & & & & & & & & & & & & \\
\hline 7.0 & 45 & $\begin{array}{l}100 \\
100\end{array}$ & $\begin{array}{l}95 \\
100\end{array}$ & 100 & & 0 & & & & & & & & & 96 & 94 & & & & & $\begin{array}{l}100, \\
91\end{array}$ & \\
\hline 7.5 & & & & & & & & & & 8 & 55 & 66 & 45 & & & & & & & & & \\
\hline 8.0 & & & & & 0 & 0 & 0 & & & 10 & 58 & 100 & 100 & 0 & 19 & 9 & 13 & 87 & & & & \\
\hline 8.5 & & & 0 & 70 & 0 & 0 & & & & & & & & & & & & & & & & \\
\hline 9.0 & & 56 & 75 & & & & & & & 0 & 10 & 36 & 71 & & 85 & 100 & & & & & & \\
\hline 10.0 & & & & & & & 70 & & & & & & & 0 & 0 & 5 & 20 & 92 & & & & \\
\hline 11.0 & & & & & & & & & & & & & & 21 & 66 & 83 & 59 & 81 & & & & \\
\hline 12.0 & & & & & & & & & & & & & & 66 & $\begin{array}{l}87 \\
100\end{array}$ & $\begin{array}{l}78 \\
100\end{array}$ & & & & & & \\
\hline 13.0 & & & & & 17 & 30 & 62 & 68 & & & & & & & & & & & & & & \\
\hline 13.5 & & & & & & 58 & 70 & & & & & & & & & & & & & & & \\
\hline 14.0 & & & & & 21 & 76 & 68 & 12 & 29 & & & & & & & & & & & & & \\
\hline 16.0 & & & & & 4 & $\begin{array}{l}48 \\
23\end{array}$ & $\begin{array}{l}85 \\
20\end{array}$ & 51 & 72 & & & & & & & & & & & & & \\
\hline 16.5 & & & & & 19 & 31 & 48 & 82 & & & & & & & & & & & & & & \\
\hline 17.0 & & & & & 0 & 0 & 0 & 23 & 74 & & & & & & & & & & & & & \\
\hline
\end{tabular}

The percentage of droplets that respond positively are presented. Ranges of $25-40$ droplets were tested for each percentage indicated.

second minor peak (R. Johnson, A. Kimmel, and P. Devreotes, unpubl; Fig. 6). Although the $\Delta 208$ mutant cells clearly did express $C A R 3$ mRNA, the same level of expression was never obtained. Instead, it appeared at a low level in early development and gradually reached a peak at $15 \mathrm{hr}$. The pattern of expression in the $\Delta 317$ cells was similar to wild type, with major and minor peaks in early and late development; however, both peaks were delayed by $3 \mathrm{hr}$. In the [cAR1 $\Delta 311$ ] cells, both peaks were delayed by $6 \mathrm{hr}$ and were briefer and lower when compared with wild-type cells. $c A R 2$ mRNAs, which are expressed in the later stages of development (C.L. Saxe III, P. Devreotes, and A. Kimmel, unpubl.l, were not detected in the $\Delta 208$ mutant cell line (data not shown).
It was also of interest to examine the expression of mRNA of the prespore gene D19 (Barklis and Lodish 1983) and prestalk A gene Dd63 (Jermyn et al. 1987). In wild-type cells, the D19 mRNA level rose to a plateau between 9 and $15 \mathrm{hr}$. There was no detectable D19 mRNA in the $\Delta 208$ mutant. The $\Delta 317$ cells expressed D19 with a nearly normal time course. The pattern of expression in the [CAR1 $\Delta 311$ ] cells was reminiscent of that of the late $P D E$ and $C A R 3$ mRNAs: After the first appearance, it was completely lost and then gradually reappeared by 18-24 hr. In wild-type cells, Dd63 mRNA appeared by $9 \mathrm{hr}$ and plateaued by $12 \mathrm{hr}$. Very little Dd63 mRNA was present in the $\Delta 208$ cells. The $\Delta 317$ cells had a wild-type $D d 63$ pattern delayed by $3 \mathrm{hr}$. In the

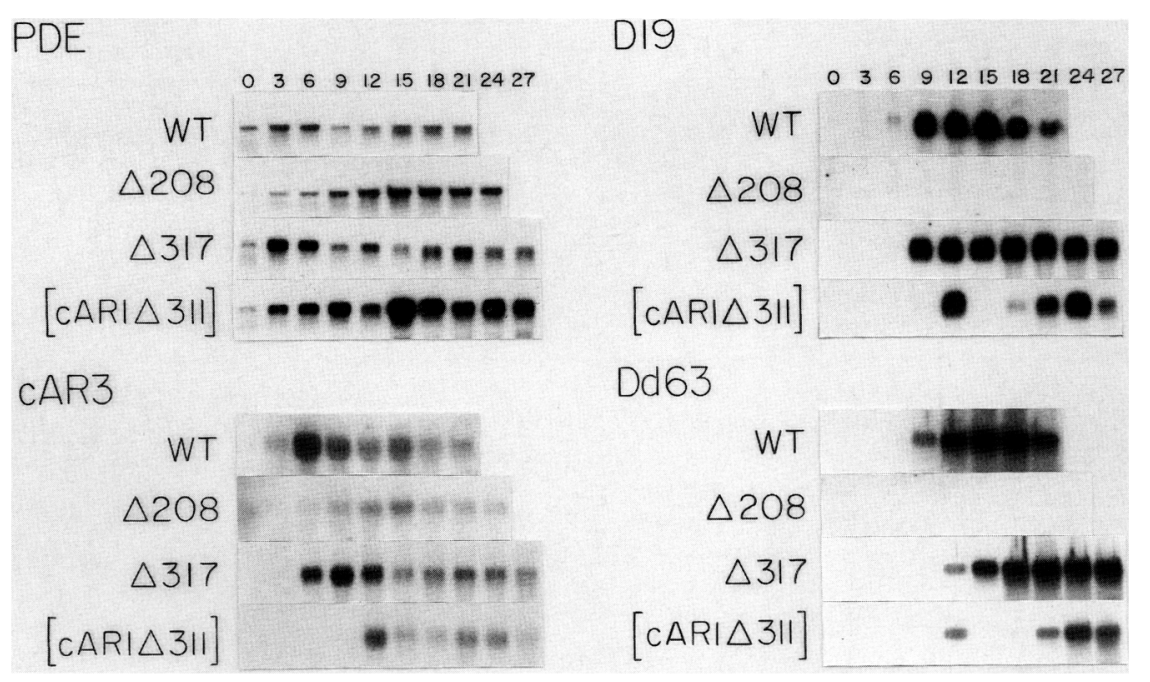

Figure 6. Gene expression of $P D E, C A R 3$, $D 19$, and $D d 63$ during development in $\Delta 208, \Delta 317$, and [cAR1 $\Delta 311]$. RNA was prepared as described in Fig. 3. Probes for cAR3, D19, $P D E$, and Dd63 were random primed. Major bands for $P D E$ are 1.9 (only at $t=0$ ), 2.4 (early development), $2.2 \mathrm{~kb}$ (late development); for $C A R 3, \sim 2.0 \mathrm{~kb}$; for $D 19$, $0.8 \mathrm{~kb}$; for $D d 63,5.8 \mathrm{~kb}$. 
[cAR1 $\Delta 311$ ] cells, $D d 63$ was expressed by $12 \mathrm{hr}$, and like the other genes, it was completely lost and then reappeared at $18 \mathrm{hr}$ and peaked at $24 \mathrm{hr}$.

\section{Frequency of homologous recombination}

DNA blots of independent clones from each transformation generally revealed three major classes of events. (1) Clones that contained only an intact copy of the cAR1 gene. These were considered to be "random" integrants. (2) Clones that contained only the predicted, altered copy as those described in Figure 1. (3) Clones that contained an altered copy as well as an intact copy. The frequency of obtaining these classes is listed in Table 2, and some examples are illustrated in Figure 7. Because the cell lines before and after transformation are haploid as evidenced by chromosome staining, the existence of class 3 suggests that the $C A R 1$ locus is duplicated or becomes duplicated during transformation. We also noted that although the formation efficiency is highest in strain HPS400, the frequency of obtaining desired mutants appeared to be highest in HC6. This effect may be due to a variable tendency toward duplication of $c A R 1$ genes in various laboratory strains. The single crossover mutants (see Fig. 1B) presented here were obtained in HC6. Extensive efforts to obtain similar "homozygous" single crossover mutants (class 2, above) have not been successful in AX3 and HPS400. Instead, individual clones that contained a classic single crossover event, as well as an intact copy of the endogenous $c A R 1$ gene (class 3 above), were routinely obtained (Fig. 7). All of the strains that contained a wild-type copy of the gene were aggregation positive. The class 2 transformants could thus be selected by screening for aggregation minus phenotype. In addition, certain clones from a transformation sometimes contained multiple additional copies of the transforming vector integrated "randomly" or within the dis-

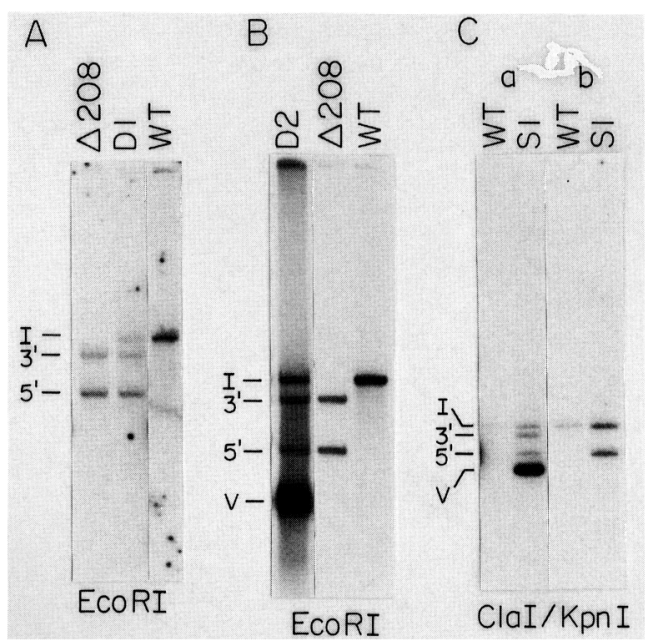

Figure 7. Evidence for duplication of the $c A R 1$ gene in some transformants. Genomic DNA from several transformants was isolated, digested with specified restriction enzymes, and probed with random-primed full-length $c A R 1 \mathrm{cDNA}(A$ and $B)$; internal fragment of $c A R 1$ from $N d e I$ to $N c o I(C, a)$; end-labeled oligomer $3(C, b)$. (I) Intact gene; $\left(3^{\prime}\right)$ junction fragment of the $3^{\prime}$ end of CAR 1 gene; $\left(5^{\prime}\right)$ junction fragment of the $5^{\prime}$ end of the car 1 gene; (V) extra copies of transforming vector presented in the transformant.

rupted $C A R 1$ locus (Fig. 7). In Table 2 these events are designated separately as simple (S) or complex $(\mathrm{C})$.

\section{Discussion}

We have presented evidence that $c A R 1$ is crucial for early development and aggregation in Dictyostelium. This is clearly demonstrated by the $\Delta 208$ mutants that develop neither cAMP-binding activity nor cAMP che-

Table 2. Efficiency of obtaining targeted transformants

\begin{tabular}{|c|c|c|c|c|c|c|c|c|}
\hline \multirow{2}{*}{$\begin{array}{l}\text { Targeting } \\
\text { strategy }^{\mathrm{a}}\end{array}$} & \multirow{2}{*}{$\begin{array}{l}\text { Parental } \\
\text { strain }\end{array}$} & \multicolumn{2}{|c|}{$C A R 1^{\mathrm{b}}$} & \multicolumn{2}{|c|}{$\operatorname{car} 1^{\mathrm{b}}$} & \multicolumn{2}{|c|}{$\operatorname{car} 1 / C A R 1^{\mathrm{b}}$} & \multirow{2}{*}{$\begin{array}{l}\text { Transformation } \\
\text { frequency }^{\mathrm{e}}\end{array}$} \\
\hline & & $\mathrm{S}^{\mathrm{c}}$ & $C^{d}$ & $S^{c}$ & $C^{d}$ & $S^{c}$ & $C^{d}$ & \\
\hline A & HC6 & 0 & 3 & 1 & 4 & 0 & 0 & $8 \times 10^{-8}$ \\
\hline A & $\mathrm{AX} 3$ & 0 & 0 & 2 & 0 & 1 & 2 & $5 \times 10^{-8}$ \\
\hline $\mathrm{A}$ & HPS400 & 0 & 0 & 2 & 5 & 2 & 5 & $5 \times 10^{-6}$ \\
\hline B & HC6 & 0 & 4 & 0 & 3 & 0 & 0 & $3 \times 10^{-8}$ \\
\hline B & $\mathrm{AX}^{\mathrm{g}}$ & 0 & 8 & 0 & 0 & 0 & 6 & $4 \times 10^{-7}$ \\
\hline B & $\mathrm{AX}^{\mathrm{g}}$ & 0 & 122 & 0 & 0 & 0 & 2 & $4 \times 10^{-6}$ \\
\hline B & HPS400" & 0 & 23 & 0 & 0 & 0 & 1 & $7 \times 10^{-7}$ \\
\hline
\end{tabular}

${ }^{\text {aSee Fig. } 1 .}$

${ }^{\mathrm{b}} C A R 1$, car1, and car1/CAR1 reflect DNA blot analysis of individual clones. (CAR1) The wild-type structure was observed; (car1) the predicted homologous recombination event was observed; (car1/CAR1) the clone contained both structures.

${ }^{\mathrm{c}}$ As indicated in the text, $\mathrm{S}$ (simple) means that clone contained no extra copies of vector.

${ }^{\mathrm{d}}$ As indicated in the text, $\mathrm{C}$ (complex) means that clone contained extra copies of transforming vector.

'Total number of transformants/total number of initial cells. Because the effects of Poisson distribution were not taken into account, this is a minimum estimate.

${ }^{\mathrm{f}}$ This distribution was biased by selection of clones that failed to aggregate.

gIn most cases, these genotypes were based on PCR data. In some cases, they were confirmed by DNA blots. 
motactic sensitivity upon starvation. All of these characteristics can be restored by constitutively expressing the protein in the $\Delta 208$ mutant ([cAR1] cells). These observations firmly establish a role for a G-protein-coupled surface receptor in a developmental program. Furthermore, disruption of $\mathrm{G} \alpha 2$, thought to be linked to cAR1, produces nearly the same phenotype (Kumagai et al. 1989). In Dictyostelium the effector of cAR1/G $\alpha 2$ is believed to be a PLC; thus, the signaling system may control phosphoinositol (PI) metabolism. G-protein-coupled receptors have not yet been implicated in the developmental programs of higher eukaryotic organisms, although there are indications that such evidence may appear. Interference with PI metabolism has dramatic effects on axis formation in Xenopus laveis (Busa and Gimlick 1989). In a Drosophila mutant, concertina, which arrests at gastrulation, the affected gene product is homologous to a G-protein $\alpha$-subunit (Parks and Wieshaus 1991).

We have begun to explore the role of cAR 1 in early development in cells that lack functional cAR1. In the $\Delta 208$ mutants cAMP-mediated signal transduction events are blocked and the vast majority of the cells fail to aggregate or differentiate when mixed with wild-type cells and thus are unable to send or receive cAMP signals. A number of early genes are still expressed, but the time course is markedly delayed or altered. These appear to be very specific defects for sensing cAMP signals as cells continue to grow normally and retain chemotactic sensitivity to folic acid.

Is cAR1 the chemoattractant receptor or is it merely required for expression of another cAR that fulfills this role? Because the $\Delta 208$ cells ultimately did display weak chemotactic responses to CAMP, an additional cAR can at least partially substitute for cARl. A likely candidate is cAR3, which is expressed in the $\Delta 208$ mutants at the time they become maximally sensitive to cAMP (after 13-16 hr). In addition, high cAMP concentrations are required for this chemotactic response, which is consistent with the observation that constitutively expressed CAR3 does have a significantly lower affinity for cAMP (R. Johnson, P. Van Haastert, and P. Devreotes, unpubl.). Although these results suggest that another cAR can substitute for cAR1 in its absence, it remains likely that CAR1 mediates aggregation and the other cARs have roles in later development during the stages at which they are maximally expressed. To address these issues, we plan to disrupt each of the other cARs.

The $\Delta 208$ mutant remained as a monolayer of cells when plated on sterile non-nutrient agar dishes at any density or in association with Enterobacter aerogenes, unlike the cAR1 antisense cell lines in which $\sim 5-20 \%$ of the cells will eventually form tiny fruiting bodies. Interestingly, the $\Delta 208$ mutants could coaggregate with wild-type cells and form spores; however, the efficiency of this synergistic aggregation was extremely low. In two experiments, when cells were mixed in $\Delta 208$ / wild-type ratios of $9: 1$, only $13 \%$ or $4 \%$ of the resulting spores scored as $\Delta 208$. This coaggregation cannot be simply replaced by exogenously providing pulsatile cAMP to de- veloping $\Delta 208$ cells during early differentiation. The $\Delta 208$ mutants were also occasionally observed to form tiny fruiting bodies near certain unidentified contaminating microorganisms present in the non-nutrient agar dish or in the Enterobacter culture. Some signal may be produced by the unidentified microorganisms, as well as the wild-type cells that can be weakly sensed by the $\Delta 208$ mutant and allow them to bypass the requirement for cAR1-mediated signal transduction in early development.

In the $\Delta 317$ cells, replacement of the expressed cAR1 with the amino-terminal four-fifths of the coding sequence by a single crossover event left several cAR1 functions intact. These $\Delta 317$ cells retained cAMP-binding activity and chemotactic sensitivity and completed the developmental program. Overexpression of the truncated protein (amino-terminal four-fifths) enabled the $\Delta 208$ mutant to differentiate [cAR1 $\Delta 311$ ] cells. In both cell lines normal fruiting bodies were formed. These observations suggest that the carboxy-terminal one-fifth of the $c A R 1$ protein is not essential for development. Several ligand-induced activities of CAR1 are believed to be crucial during early development. First, excited cARl activates $G \alpha 2$; second, cARl is phosphorylated on its carboxy-terminal domain, which presumably attenuates its G-protein-activating capacity. Considering that the $\Delta 317$ and [CAR1 $\Delta 311]$ cells differentiate normally, the aminoterminal four-fifths of the $c A R 1$ protein must contain the $\mathrm{G} \alpha 2$ interaction domain as well as at least some of the crucial phosphorylation site(s). What, then, is the role of the last one-fifth of the $c A R 1$ protein? The $\Delta 317$ mutant has a similar course of mRNA profiles as the wild-type cell, but its maximal cAMP-binding was greatly delayed. This inconsistency in the pattern of mRNA versus the cAMP-binding activity in the $\Delta 317$ mutant may suggest that the protein has a rapid turnover rate in early development. The carboxy-terminal onefifth of cAR1 may be involved in resistance to degradation by aggregation stage protease(s). Alternatively, the last one-fifth of the $C A R 1$ protein may be involved in the targeting of this receptor to cell surface.

The small genome size $\left(3 \times 10^{4} \mathrm{~kb}\right)$ and the availability of several selection systems make Dictyostelium very amenable to molecular genetic manipulation. It may provide an important model system to study development. The ease in obtaining null mutants by homologous recombination further advances the potential use of this organism to study a wide variety of fundamental biological processes (DeLozanne and Spudich 1987; Witke et al. 1987). Initially, when we encountered difficulty in obtaining $c A R 1$ null mutants, we were concerned that developmentally regulated genes might be more difficult to target, limiting the versatility of the system. Our evidence suggests instead that certain genes, such as $c A R 1$, can become duplicated; yet it is still possible to target all genomic copies by homologous recombination to generate null mutants. The frequency of obtaining desired mutants was not necessarily correlated with overall transformation efficiency, possibly due to the extent of $c A R 1$ gene duplication present in the 
different strains. The extent of these putative duplications is currently being assessed by megabase mapping techniques. The $\Delta 317$ mutant and the [CARl] and [cAR1 $\Delta 311$ ] rescue of the $\Delta 208$ mutant presented in this report open the way to create stable mutated $c A R$ cell lines to further study the role of G-protein-mediated signal transduction pathways in development. These results further demonstrate the feasibility of gene replacement and complementation in Dictyostelium, which has now been demonstrated for a wide variety of genes (DeLozanne and Spudich 1987; Witke et al. 1987; Jung and Hammer 1990).

\section{Materials and methods}

Vector construction and transformation of Dictyostelium

Double crossover vector A BamHI-BglII fragment from Neol $\triangle$ XTBR (A15TX; Cohen et al. 1986) containing the G418 ${ }^{\mathrm{R}}$ cassette (NPT1 gene flanked by the actin 15 promoter and the actin 15 terminator) was inserted into the $C A R 1$ cDNA clone p6B (Klein et al. 1988) at the BclI site located at nucleotide 627. In the numbering of nucleotide bases in this article, the first base of the cAR1-coding sequence is taken as nucleotide 1 . The final plasmid has the G418 ${ }^{\mathrm{R}}$ cassette terminator region adjacent to the 5' arm of $c A R 1$. The vector was linearized with BamHI$X$ hoI-NdeI and purified by phenol/chloroform and chloroform extraction. After ethanol precipitation the DNA was dissolved in TE.

Single crossover vector An internal fragment of cAR1 cDNA (nucleotides 22-954) was subcloned into pBSA15 at its EcoRV site (pBSA15 is Bluescript containing the G418 ${ }^{\mathrm{R}}$ cassette of A15TX in its BamHI-EcoRI site). The fusion added 20 irrelevant amino acid residues to the truncated cAR1. The terminator of the $\mathrm{G} 418^{\mathrm{R}}$ cassette is adjacent to the $5^{\prime}$ end of the $c A R 1$ gene, and the T3 primer of Bluescript is adjacent to its $3^{\prime}$ end. The vector was lineanzed with $N d e I$ and extracted as described above.

DNA was introduced into Dictyostelium, strain HC6 (Coukell 1975), AX3, or HPS400 (Podgorski and Deering 1984) by electroporation (Howard et al. 1988) at $1.3 \mathrm{kV}$ with a $\tau$ value of $0.7-1.1 \mathrm{msec}$. After $24 \mathrm{hr}$, cells were divided into 96-well plates and G418 was introduced at $6 \mu \mathrm{g} / \mathrm{ml}$ (HC6) or $10 \mu \mathrm{g} / \mathrm{ml}$ (AX3, HPS400). Medium was changed weekly thereafter. Confluent wells were transferred into 24 -well plates and maintained.

pThylcARl, pB18cARA(311-392) (R. Johnson, R. Vaughan, M. Caterina, P.J.M. Van Haastert, and P.N. Devreotes, unpubl.), and pATANB43 (Dynes and Firtel 1989) were used for complementation. The genotypes of the formed cell lines are listed in Table 3, together with colloquial names used throughout the text. The cell line [cAR1 $\Delta 311]$ was constructed by cotransformation of pB18cAR $\Delta(311-392)$ and pATANB43 into $\Delta 208$.

\section{$D N A$ and RNA preparation and analysis}

For PCR, DNA was prepared from pools of 3-12 wells. Onetenth of the pooled DNA was used for PCR screening with a modification of the protocol included with Amplitaq (PerkinElmer). Genomic DNA was prepared as described (Sun et al. $1990)$ and digested with the indicated restriction enzymes. It was then electrophoresed in $0.7 \%$ agarose gels and transferred to nitrocellulose. For RNA blots individual clones were grown in suspension to $5 \times 10^{6} \mathrm{cells} / \mathrm{ml}$, washed, and plated on non-nutrient agar dishes. Total RNA was prepared as described (Nellen
Table 3. Summary of cell lines

\begin{tabular}{ll}
\hline Name & Genotype $^{\text {a }}$ \\
\hline WT (HC6, AX3) & CAR1, THY \\
WT (HPS400) & CAR1, thy \\
$\Delta 208$ & car1 :: NPT1 at 627, THY \\
$\Delta 317$ & car1 :: Bluescript-NPT1 at 954, THY \\
[cAR1] & [Thy cAR1]/car1 :: NPT1 at 627, thy \\
[CAR1 $\Delta 311]$ & [B18cAR1 $\{311-392$ ], \\
& pATANB43]/car1 :: NPT1 at 627, THY \\
\hline
\end{tabular}

${ }^{a}$ Genes in uppercase letters are wild type; lowercase letters indicate that the gene is mutated. Designation following double colon gives indication of the mutation.

et al. 1987). Either 5 or $10 \mu \mathrm{g}$ of RNA per lane was electrophoresed in $1.2 \%$ or $1.4 \%$ formaldehyde-agarose gels and transferred to nitrocellulose (Maniatis et al. 1982). DNA probes were made by the random priming method from fragments isolated from agarose gels (Feinberg and Vogelstein 1983).

The sequences of the oligonucleotides used for either PCR or genomic DNA blots and illustrated in Figure 1 are the following:

\section{5'-CCTCTCTTTTCTTTTATTTTCAAATAATTATAGAACGC \\ 2. 5'-CCTGGGAACATAGTTGTACCACC \\ 3. 5'-CCGAATTCATGGGTCTTTTAGATGG \\ 4. 5'-CCGAATTCTCAATTATTTCCTTGACCATTTG \\ 5. 5'-CGGAATTAACCCTCACTAAAGGG}

\section{cAR1 protein and $C A M P$-binding assay}

cAMP-binding assays were carried out as described previously (Van Haastert and Kien 1983). Western blots were carried out on membranes prepared by the ammonium sulfate method and dissolved in SDS-gel loading buffer at a final density of $5 \times 10^{7}$ cell equivalents per milliliter. Samples were subjected to SDSPAGE and transferred to nitrocellulose, and polyclonal rabbit antisera against cAR1 (Klein et al. 1987) and ${ }^{125}$ I-labeled protein A were used to detect the receptor protein. Photoaffinity labeling of intact cells with $\mathrm{N}_{3}{ }^{32} \mathrm{P}$-labeled cAMP was carried out as described previously (Theibert et al. 1984). Samples were subjected to SDS-PAGE, stained with Coomassie blue, destained, dried on Whatmann $3 \mathrm{MM}$ paper, and autoradiographed on Kodak AR X-ray film at $-70^{\circ} \mathrm{C}$ with intensitying screens for 3-6 days.

\section{Developmental program}

Cells were allowed to develop in shaken suspension (100 rpm) in development buffer (DB) $\left(5 \mathrm{mM} \mathrm{Na} \mathrm{HPO}_{4}, 5 \mathrm{mM} \mathrm{KH}_{2} \mathrm{PO}_{4}, 2\right.$ mM MgSO $4,0.2 \mathrm{mM} \mathrm{CaCl}_{2}$ ) at $2 \times 10^{7}$ cells $/ \mathrm{ml}$ or on the surface of non-nutrient agar plates (DB, $1 \%$ agar) at $6.4 \times 10^{5} \mathrm{cell} / \mathrm{cm}^{2}$.

\section{Chemotaxis}

For chemotaxis, cells were developed for the specified time on non-nutrient agar plates. The cells were then washed into DB and used in the small population assay to determine the chemotactic responsiveness toward cAMP or folic acid (Konijn 1970). The cells were also time-lapse videotaped to observe the chemotaxis of each strain. 


\section{Acknowledgments}

We thank Dr. Barrie Coukell for providing HC6, Yanshu Wang for construction of the double crossover vector, Dr. Karl Saxe for providing several oligomers, Pam Lilly for providing sequence for oligomer 2, Ron Johnson and Dr. Rick Firtel for vector pTHY cAR1, Mike Caterina for pBS18cAR1 $\Delta(311-392)$, Dr. Jacob Franke for providing phosphodiesterase (PDE) cDNA, Dr. Jeff Williams for providing Dd63 cDNA, Dr. Daphne Blumberg for providing D19 cDNA, Dr. Susan Michaelis for her comments on the manuscript, and Peggy Ford for secretarial assistance. Karyotype of cell lines was kindly determined by Dr. Barrie Coukell, University of York. This work was supported in part by a National Institutes of Health grant (GM R01-34933-04) to P.N.D.

The publication costs of this article were defrayed in part by payment of page charges. This article must therefore be hereby marked "advertisement" in accordance with 18 USC section 1734 solely to indicate this fact.

\section{References}

Barklis, E. and H.F. Lodish. 1983. Regulation of Dictyostelium discoideum mRNAs specific for prespore or prestalk cells. Cell 32: 1139-1148.

Busa, W.B. and R.L. Gimlick. 1989. Lithium-induced teratogenesis in frog embryos prevented a polyphosphoinositide cycle intermediate or a diacylglycerol analog. Dev. Biol. 132: 315-324.

Cohen, S.M., D. Kecht, H.F. Lodish, and W.F. Loomis. 1986. DNA sequences required for expression of a Dictyostelium actin gene. EMBO J. 5: 3361-3366.

Coukell, M.B. 1975. Parasexual genetic analysis of aggregationdeficient mutants of Dictyoselium discoideum. Mol. Gen. Genet. 142: 119-135.

DeLozanne, A., and J.A. Spudich. 1987. Disruption of the Dictyostelium myosin heavy chain gene by homologous recombination. Science 236: 1086-1091.

Devreotes, P. 1989. Dictyostelium discoideum: A model system for cell-cell interactions in development. Science 245: 1054-1058.

Devreotes, P.N. and J. Sherring. 1985. Kinetics and concentration dependence of reversible cAMP-induced modification of the surface cAMP receptor in Dictyostelium discoideum. $J$. Biol. Chem. 260: 6378-6384.

Dixon, R.A.F., I.S. Sigal, E. Rands, R.B. Register, M.R. Candelore, A.D. Blake, and C.D. Strader. 1987. Ligand binding to the $\beta$-adrenergic receptor involves its rhodopsin-like core. Nature 326: 73-77.

Dynes, J.L. and R.A. Firtel. 1989. Molecular complementation of a genetic marker in Dictyostelium using a genomic DNA library. Proc. Natl. Acad. Sci. 86: 7966-7970.

Faure, M., J. Franke, A.L. Hall, G.J. Podgorski, and R.H. Kessin. 1990. The cyclic nucleotide phosphodiesterase gene of Dictyostelium discoideum contains three promoters specific for growth, aggregation and late development. Mol. Cell. Biol. 10: $1921-1930$.

Feinberg, A.P. and B. Vogelstein. 1983. A technique for radiolabeling DNA restriction endonuclease fragments to high specific activity. Anal. Biochem. 132: 6-13.

Gerisch, G. 1987. Cyclic AMP and other signals controlling cell development and differentiation in Dictyostelium. Annu. Rev. Biochem. 56: 853-879.

Gomer, R.H., D. Armstrong, B.H. Leichtling, and R.A. Firtel. 1986. cAMP induction of prespore and prestalk gene expression in Dictyostelium is mediated by the cell-surface cAMP receptor. Proc. Natl. Acad. Sci. 83: 8624-8628.

Haribabu, B. and R.P. Dottin. 1986. Pharmacological characterization of AMP receptors mediating gene regulation in Dictyostelium discodeum. Mol. Cell. Biol. 6: 2402-2408.

Howard, P.K, K.G. Ahern, and R.A.Firtel. 1988. Establishment of a transient expression system for Dictyostelium discoideum. Nucleic Acids Res. 16: 2613-2623.

Janssens, P.M.W. and P.J.M. Van Haastert. 1987. Molecular basis of transmembrane signal transduction in Dictyostelium discoideum. Microbiol. Rev. 51: 396-418.

Jermyn, K.A., M. Berks, R.R. Kay, and J.G. Williams. 1987. Two distinct classes of prestalk-enriched mRNA sequences in Dictyostelium discoideum. Development 100: 745-755.

Jung, G. and J. Hammer III. 1990. Generation and characterization of Dictyostelium cells deficient in a myosin I heavy chain isoform. J. Cell Biol. 110: 1955-1964.

Kimmel, A.R. 1987. Different molecular mechanisms for cAMP regulation of gene expression during Dictyostelium development. Dev. Biol. 122: 163-171.

Klein, P., A. Theibert, D. Fontana, and P.N. Devreotes. 1985. Identification and cAMP-induced modification of the CAMP receptor in Dictyostelium discoideum. I. Biol. Chem. 260: $1757-1764$.

Klein, P., R. Vaughan, J. Borleis, and P. Devreotes. 1987. The surface cyclic AMP receptor in Dictyostelium. I. Biol. Chem. 262: 358-364.

Klein, P.S., T.J. Sun, C.L. Saxe III, A.R. Kimmel, R.L. Johnson, and P.N. Devreotes. 1988. A chemoattractant receptor controls development in Dictyostelium discoideum. Science 241: 1467-1472.

Konijn, T.M. 1970. Microbiological assay of cyclic 3', 5'-AMP. Experientia 26: 367-369.

Kumagai, A., M. Pupillo, R. Gundersen, R. Miake-Lye, P.N. Devreotes, and R.A. Firtel. 1989. Regulation and function of $\mathrm{G}_{\alpha}$ protein subunits in Dictyostelium. Cell 57: 265-275.

Maniatis, T., E.F. Fritsch, and J. Sambrook. 1982. Molecular cloning. A laboratory manual. Cold Spring Harbor Laboratory, Cold Spring Harbor, New York.

Mann, S. and R. Firtel. 1987. Cyclic AMP regulation of early gene expression in Dictyostelium discoideum: Mediation via the cell surface cyclic AMP receptor. Mol. Cell. Biol. 7: 458-469.

Nellen, W., S. Datta, C. Reymond, A. Sivertsen, S. Mann, T. Crowley, and R.A. Firtel. 1987. Molecular biology in Dictyostelium: Tools and applications. Methods Cell Biol. 28: 6799.

Newell, P.C., G.N. Europe-Finner, N.V. Small, and G. Liu. 1988. Inositol phosphates, G-proteins and ras genes involved in chemotactic signal transduction of Dictyostelium. I. Cell Sci. 89: 123-127.

Oyama, M. and D.D. Blumberg. 1986. Interaction of cAMP with the cell-surface receptor induces cell-type-specific maNA accumulation in Dictyostelium discoideum. Proc. Natl. Acad. Sci. 83: 4819-4823.

Parks, S. and E. Wieshaus. 1991. The Drosophila gastrulation gene concertina encodes a G $\alpha$-like protein. Cell 64: 447-458.

Podgorski, G.J. and R.A. Deering. 1984. Thymidine-requiring mutants of Dictyostelium discoideum. Mol. Cell. Biol. 4: 2784-2791.

Saxe, C.L. III, R. Johnson, P.N. Devreotes, and A. Kimmel. 1991. Analysis of the cAMP receptor gene of Dictyostelium: Evidence for a multigene family. Genes 4 Dev. 5: 1-8.

Schaap, P. and R. van Driel. 1985. Induction of post-aggregative differentiation in Dictyostelium discoideum by cAMP. Evidence of involvement of the cell surface cAMP receptor. Exp. Cell Res. 159: 388-398. 
Sun, T.J., P.J.M. Van Haastert, and P.N. Devreotes. 1990. Surface cAMP receptors mediate multiple responses during development in Dictyostelium: Evidenced by antisense mutagenesis. J. Cell Biol. 110: 1549-1554.

Theibert, A., P. Klein, and P.N. Devreotes. 1984. Specific photoaffinity labelling of the cAMP surface receptor in Dictyos telium discoideum. J. Biol. Chem. 259: 12318-12321.

Van Haastert, P.J.M. 1984. Guanine nucleotides modulate cell surface cAMP-binding sites in membranes from Dictyostelium discoideum. Biochem. Biophys. Res. Commun. 124: 597-604.

Van Haastert, P.J.M. and E. Kien. 1983. Binding of cAMP derivatives to Dictyostelium discoideum cells. Activation mechanism of the surface cAMP receptor. J. Biol. Chem. 258: $9636-9642$.

Van Haastert, P.J.M., M.J. de Vries, L.C. Penning, E. Roovers, J. van der Kaay, C. Erneux, and M.M. van Lookeren Campagne. 1989. Chemoattractant and guanosine $5^{\prime}-[\gamma$-thio]triphosphate induce the accumulation of inositol 1,4,5-trisphosphate in Dictyostelium cells that are labelled with $\left[{ }^{3} \mathrm{H}\right]$ inositol by electroporation. Biochem J. 258: 577-586.

Vaughan, R. and P.N. Devreotes. 1988. Ligand-induced phosphorylation of the cAMP receptor from Dictyostelium discoideum. I. Biol. Chem. 263: 14538-14543.

Witke, W., N. Wolfgang, and A. Noegel. 1987. Homologous recombination in the Dictyostelium $\alpha$-actinin gene leads to an altered mRNA and lack of the protein. $E M B O ~ / .6: 4143-$ 4148 . 


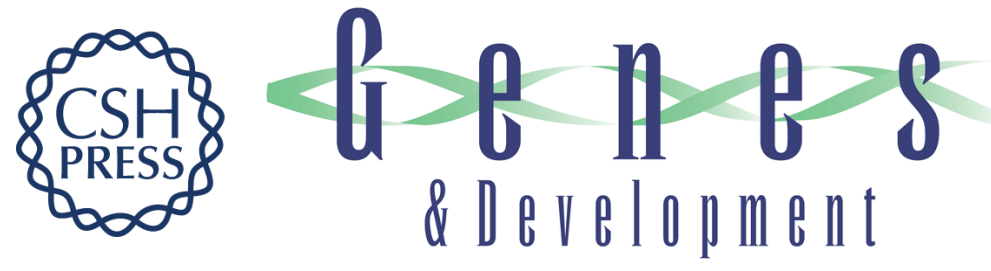

\section{Gene targeting of the aggregation stage cAMP receptor CAR1 in Dictyostelium.}

T J Sun and P N Devreotes

Genes Dev. 1991, 5:

Access the most recent version at doi:10.1101/gad.5.4.572

References This article cites 39 articles, 22 of which can be accessed free at:

http://genesdev.cshlp.org/content/5/4/572.full.html\#ref-list-1

License

Email Alerting

Service

Receive free email alerts when new articles cite this article - sign up in the box at the top right corner of the article or click here.

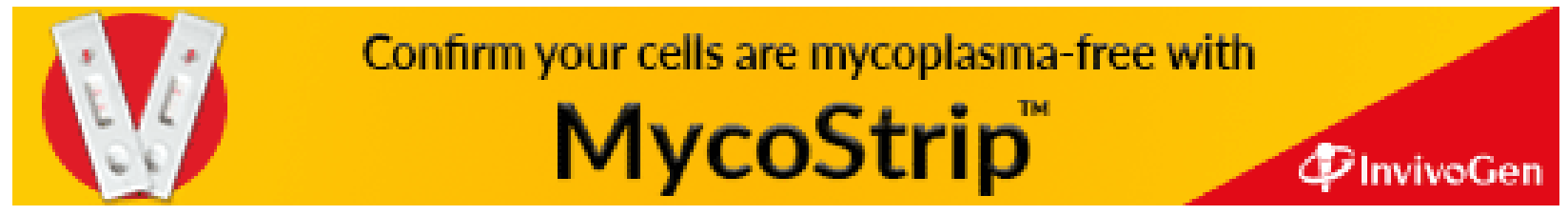

